\author{
Devanny Gumulya S.Sn, M.Sc ${ }^{1}$ dan Nathalisa Octavia S.Sn \\ Program Studi Desain Produk \\ Universitas Pelita Harapan \\ ${ }^{1}$ devanny.gumulya@upha.edu
}

\title{
KAJIAN ASIMILASI BUDAYA PADA SANDAL DAN TAS WANITA CINA PERANAKAN
}

\begin{abstract}
Abstrak. Budaya Cina peranakan merupakan hasil dari proses asimilasi beberapa budaya. Namun budaya Cina peranakan kini tidak lagi dikenal oleh masyarakat modern karena keunikannya yang kaya akan unsur ornamen yang bersifat filosofis tergantikan oleh budaya modern yang serba praktis dan fungsionalis. Paper ini mencoba mengkaji latar belakang sejarah dan keunikan budaya cina peranakan pada produk fesyen sandal dan tas. Ditemukan asimilasi budaya Jawa, Belanda, dan Cina yang sangat unik. Perbedaan dari ketiga budaya ini saling mempengaruhi satu sama lain dan menghasilkan keunikan tersendiri yang tertuang pada kekayaan budaya Cina peranakan, contoh pada tas cina peranakan ada motif angsa karena pengaruh budaya Belanda.
\end{abstract}

Kata kunci : Asimilasi Budaya, Cina Peranakan, Busana Wanita

\begin{abstract}
Cina Peranakan culture is a result of assimilation from different cultures. Unfortunately, nowadays this unique culture is almost forgotten by contemporary societies who prefer modern culture in which practicality and functionality are important factor to considerate rather than ornamentation. This paper tries to elaborate the historic point of view to gain closer understanding and synthesize the culture uniqueness with Sandal and Bag as object study case. The conclusion is Cina Peranakan culture is melting pot between Java, Dutch and Chinese Cultures. The difference from the three cultures produces a very unique culture. For example, there is goose motif in the bag as result of Dutch culture.
\end{abstract}

Keywords : Culture assimilation, Cina Peranakan culture, Woman Fashion

\section{Pendahuluan}

Sepanjang sejarah, Indonesia dikenal sebagai negara maritim yang multikultur akibat hubungan dagang antar bangsa seperti Eropa, Cina, Arab dll. Hal ini mendorong Indonesia untuk mengembangkan budayanya sendiri dengan pengaruh - pengaruh budaya lainnya. Salah satu budaya yang mempengaruhi Indonesia dan adalah budaya Cina berasimiliasi dengan budaya lokal dan disebut dengan Budaya Cina Peranakan.

Asal mula berawal dari hubungan dagang antara Indonesia dengan Cina terbentuk sejak berabad-abad yang lalu. Melalui hubungan dagang, banyak orang-orang Cina kemudian menetap dan memiliki keturunan dari perempuan setempat yang lahir di beberapa bagian Indonesia dan disebut sebagai Cina peranakan. Selain mengandung budaya Cina dan Indonesia, budaya Cina peranakan juga mendapat pengaruh dari budaya barat, khususnya Belanda. Masa penjajahan Belanda yang berlangsung cukup lama di Indonesia mengakibatkan terserapnya budaya negara 
tersebut masuk ke dalam pola hidup masyarakat di saat itu. Interaksi masyarakat dari ketiga negara yang berbeda tersebutlah yang menjadi faktor utama terciptanya keindahan budaya Cina peranakan. Dapat disimpulkan bahwa budaya Cina peranakan merupakan silang budaya antara budaya Indonesia (mayoritas Jawa), budaya barat (mayoritas Belanda), dan budaya Cina.

\subsection{Rumusan Permasalahan}

Permasalahan yang mau dijawab di paper ini adalah :

1. Latar belakang sejarah budaya Cina Peranakan

2. Analisa artefak desain produk (Sandal dan Tas) sebagai studi asimilasi budaya

3. Memberi wawasan baru bahwa ada budaya lain yang mempengaruhi budaya cina peranakan, yaitu budaya Belanda.

\subsection{Metode Penelitian}

Metode Kajian diuraikan dalam tahapan-tahapan sebagai berikut :

1. Observasi ke Restoran Dapur Babah Elite, Jakarta

2. Observasi ke Museum Peranakan Tangerang, Banten

3. Observasi ke Museum Peranakan Singapore, Singapura

4. Observasi ke Little Shophouse, Singapura

5. Observasi ke Rumah Bebe, Singapura

6. Studi Literatur

\section{Budaya Cina Peranakan}

Menurut Prof. Gondomo, Ph.D. (dalam Kwa, Davis, dkk., 2009); kebudayaan adalah segala sesuatu yang diteruskan atau diwariskan dari satu orang kepada orang lain sebagai anggota masyarkat, dengan cara belajar, disuruh (atau tidak disuruh) menirukan, diberi contoh atau teladan, tetapi bukan Sesutu yang diteruskan dan diwariskan secara genetik. Oleh sebab itu, semua ciri fisik seperti warna kulit, bentuk mata, hidung, dan lainnya yang diperoleh dari ayah dan ibu bukannlah suatu kebudayaan. Nilai-nilai kebudayaan dapat diperoleh dengan cara memperhatikan atau meniru penggunaan bahasa, cara dan selera makan, cara memasak, cara duduk, sopan santun, tutur kata, tata nilai, keyakinan religious, pandangan hidup, keterampilan, kebiasaan, dari orang tua, keluarga, teman, guru, pemimpin, raja dan sebagainya.

Kaum Cina peranakan sebagian besar merupakan campuran dari kaum migran Hokkian dari provinsi selatan di Cina dengan perempuan setempat. Pengaruh pihak perempuan dalam rumah tangga campuran ini melahirkan suatu budaya yang unik dan khas yang diturunkan dari generasi ke generasi, hingga pada saat terbentuknya komunias peranakan di Jawa yang solid dan signifikan. (Mona Lohanda dalam Kwa, David, dkk., 2009). Dalam kehidupan sehari-hari, 
kebudayaan golongan ini merupakan campuran dari tiga unsur yaitu Jawa, Cina, dan Belandawalaupun ada juga sebagian kecil peranakan yang terpengaruh budaya di luar pulau Jawa.

\subsection{Kasut Manek}

Sejak pertengahan 1800-an, kaum nyonya Cina peranakan diharapkan untuk menguasai semua kegiatan domestic arts sebelum mereka menikah; mulai dari memasak, mengurus rumah dan juga menguasai teknik embroidery dan beadwork. Sebelum menikah, kaum pihak perempuan harus menunjukan kemampuannya dengan membuat produk untuk digunakan pada berbagai acara, salah satunya adalah membuat alas kaki. Bentuk alas kaki pertama dengan teknik embroidery adalah kasut kodok, yang bentuknya merupakan persilangan antara slip-on-toe dan slipper; disebut juga dengan sebutan kasut tongkang (Chinese bumboat shoes). Selanjutnya, model yang lebih rata dan mirip seperti alas kaki kamar mandi pada masa kini disebut kasut seret.
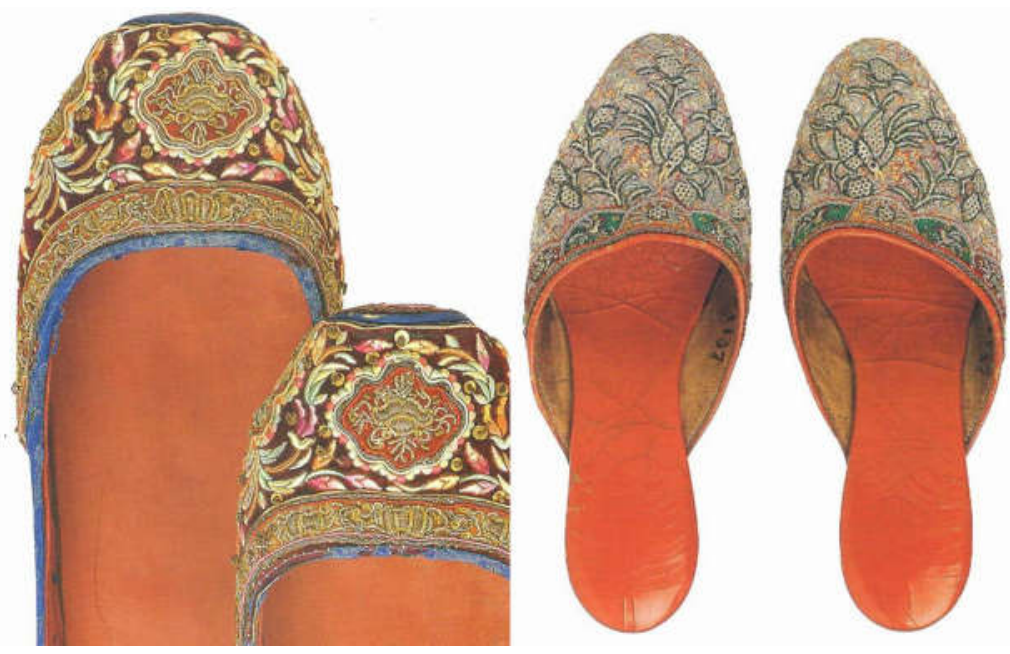

Gambar 1. Kasut Kodok dan Kasut Seret

Sumber: The Nyonya Kebaya, 2004

Kasut kodok dan kasut seret terbuat dari sutera atau beludru, dihiasi dengan embroidery menggunakan benang emas atau silver, dan menggunakan genuine leather sebagai sol. Kasut kodok dan kasut seret digunakan sebagai padanan baju panjang. Setelah baju panjang tidak lagi digunakan dan beralih ke kebaya, lahirlah kasut manek sebagai bentuk alas kaki yang lebih modern. Kata manek berarti manik dalam bahasa Melayu. Berbeda dengan kasut kodok dan kasut seret yang hanya menggunakan teknik embroidery, kasut manek dilengkapi dengan teknik beadwork. Teknik beadwork pada awalnya hanyalah unsur ornamental yang diaplikasikan pada benda-benda dekoratif seperti taplak meja atau tempat tidur pengantin, dan hanya digunakan 
pada saat upacara atau acara tertentu. Namun, memasuki era kebaya modern, pengaplikasiannya meluas menjadi unsur dekoratif sepatu dan tas juga.

Beadwork pada kasut manek berkembang dari waktu ke waktu, dengan pengaruh dari budaya Eropa. Bahan sutera dan beludru digantikan dengan bahan kanvas yang ringan; bentuk bagian ujung jari yang awalnya membulat semakin lama semakin meruncing, dan heels rendah serta model open-toe bermunculan. Namun, selain dari segi bentuk, motif yang ada pada kasut manek menunjukan bagaimana pengaruh budaya Eropa terserap masuk ke dalam budaya Cina peranakan. Seperti halnya kebaya, motif yang sering digunakan pada kasut manek adalah motif bunga, hewan, figur atau geometri.
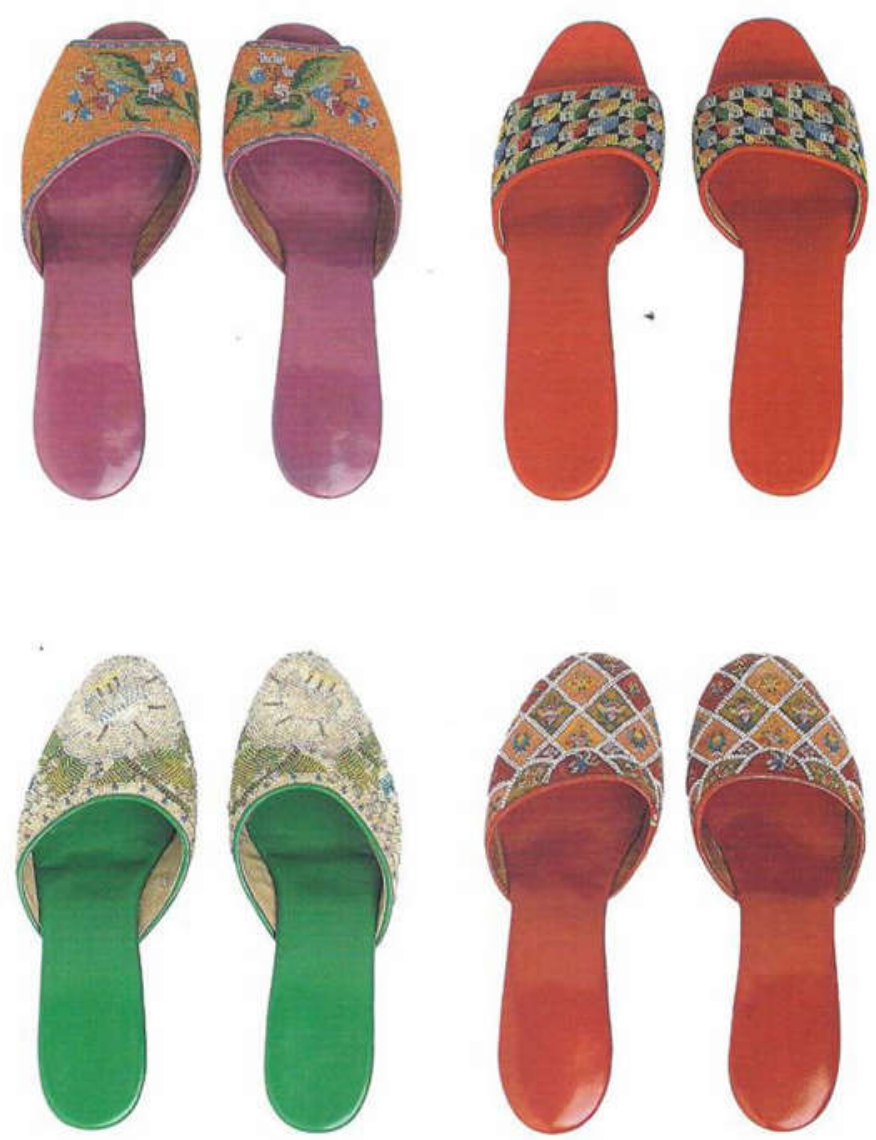

Gambar 2. Kasut Manek

Sumber: The Nyonya Kebaya, 2004

Pada awalnya, saat kasut manek hanya digunakan untuk upacara penting seperti pernikahan, pemilihan motif sangatlah disesuaikan dengan arti yang baik. Motif yang sering digunakan adalah gambar ikan dan kalelawar sebagai perlambang kebahagiaan, bebek perlambang kesetiaan, buah persik perlambang umur panjang, dan phoenix perlambang pasangan 


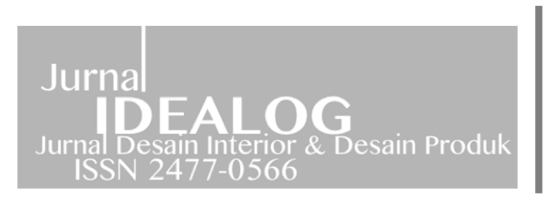

pengantin. Selanjutnya, ketika kasut manek mulai lebih sering digunakan sebagai alas kaki sehari-hari sebagai padanan kebaya sulam, berkembanglah motif-motif baru yang lebih bervariatif mengikuti perkembangan kebaya; seperti motif bunga mawar dan bunga daisy yangmerupakan pengaruh Eropa. Selain itu muncul pula motif figur-figur lainnya yang dipengaruhi oleh dongeng Eropa.

\section{PROSES AKULTURASI (KASUT MANEK)}

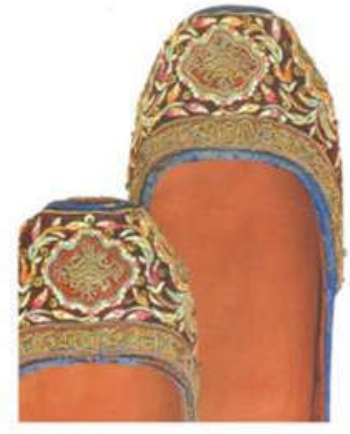

Kasut Kodok

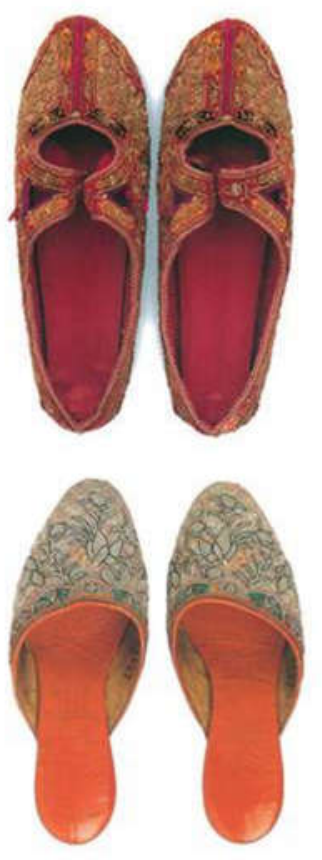

Kasut Seret
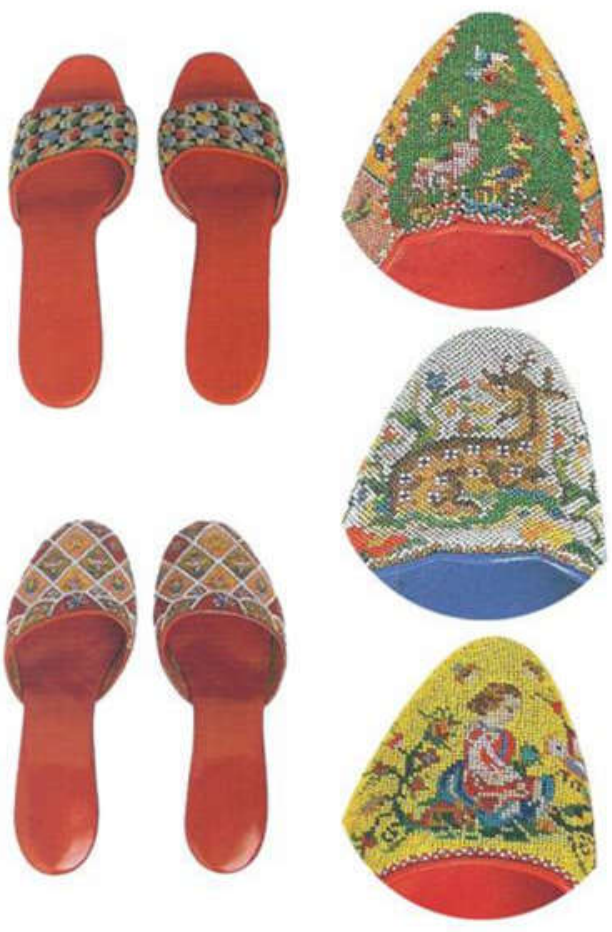

Kasut Manek

Gambar 3. Timeline Kasut Manek

Sumber: Data Pribadi, 2013

\subsection{Tas dalam Budaya Cina}

Tas merupakan wadah untuk membawa barang bawaan, yang berkembang sesuai dengan perkembangan zaman dan lingkungan di sekitarnya. Untuk menelaah bagaimana kaum Cina peranakan membawa tas dan bagaimana bentuk-bentuknya, dapat diamati melalui menelaah terlebih dahulu bagaimana tas dari negeri Cina itu sendiri. Pada zaman dinasti Ming (13681644), atau dapat dikatakan sekitar abad ke-14 sampai abad ke-17, tas lebih tepat disebut sebagai pouch atau purse. Pakaian pada zaman dinasti Ming penuh dengan ornamen-ornamen dan kain yang menutupi seluruh tubuh, bentuknya pun melebar dari bawah dada sampai seujung mata kaki yang dikencangkan dengan belt dibagian pinggang, dengan sleeves bagian tangan yang melebar 
dari pundak kearah pergelangan tangan. Purse digantungkan pada belt, selain untuk membawa barang bawaan juga sebagai hiasan yang menjadi penanda status sosial seseorang.

Ukurannya purse spesifik hanya seukuran benda yang termuat didalamnya, begitu pula bentuknya mengikuti bentuk benda yang dibawa. Fungsi purse pada zaman ini beranekaragam, seperti untuk menaruh benda tajam, untuk membawa koin, atau untuk membungkus hadiah yang berisi perhiasan, parfum atau barang berharga lainnya.
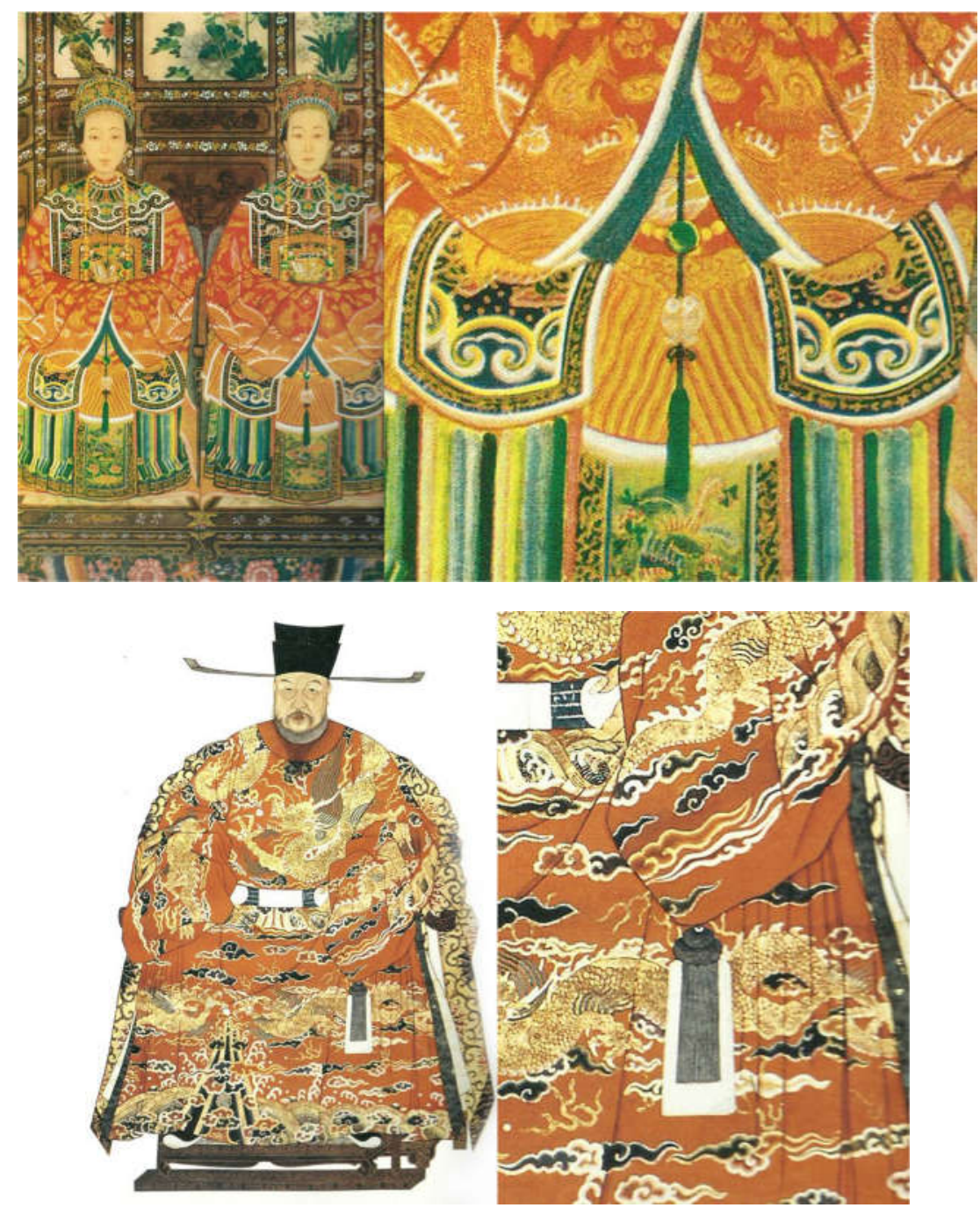

Gambar 4. Awal Mula Penggunaan Pouch

Sumber: Chinese Dress "From the Qing Dynasty to the Present", 2008

Walaupun bentuknya bervariasi sesuai barang yang dibawa, namun purse pada zaman tersebut memiliki karakter umum yaitu: terbuat dari beludru, genuine leather, atau sutera, dan dijahit dengan benang berwarna merah, kuning, biru, emas atau perak. 

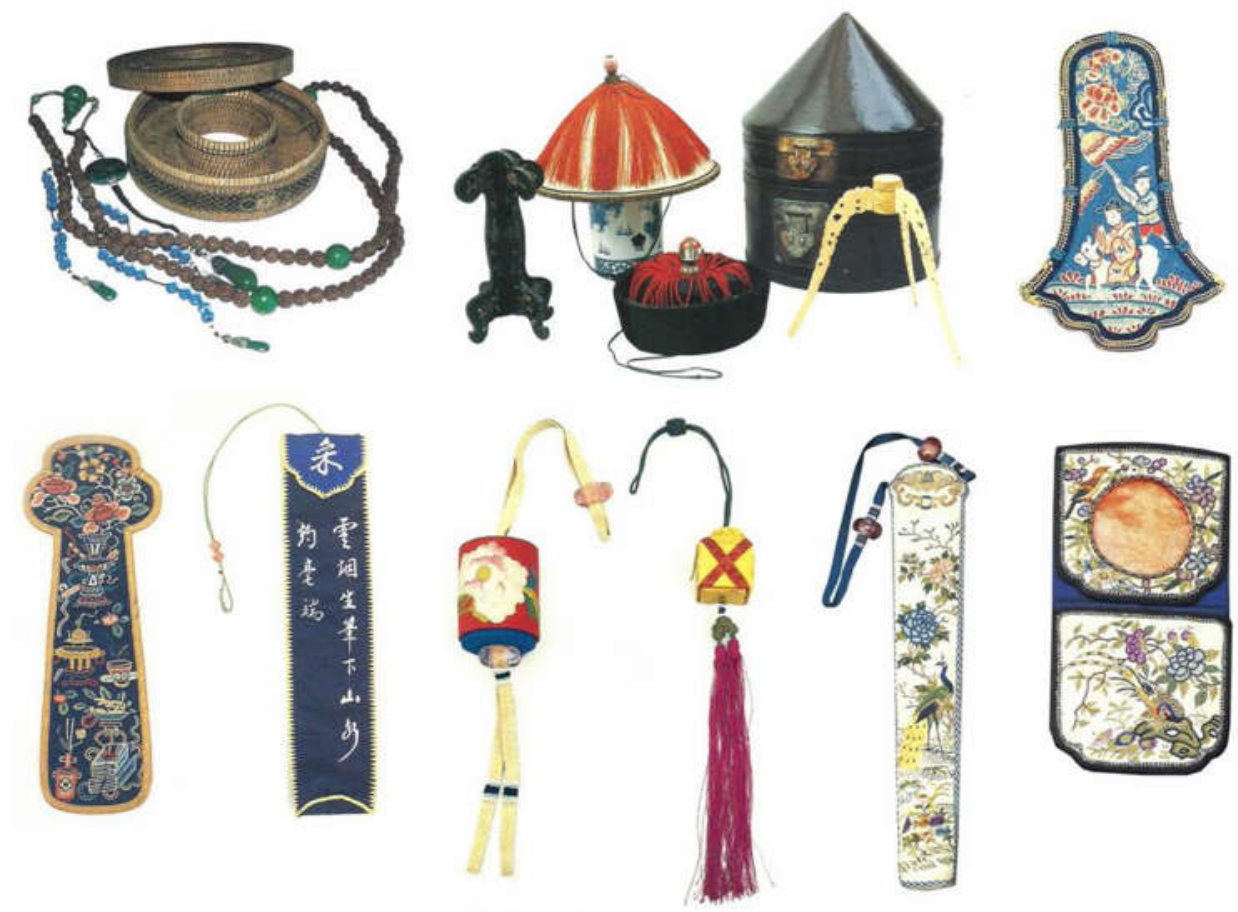

Gambar 5. Jenis-Jenis Pouch

Sumber: Chinese Dress "From the Qing Dynasty to the Present", 2008

Setelah runtunya dinasti Ming, dimulailah periode dinasti Qing yang dikuasai oleh penjajah Manchu pada tahun 1644-1911, atau dapat dikatakan sekitar abad ke-16 sampai abad ke-16 sampai awal abad ke-20. Pada zaman ini, pakaian orang Cina tidak lagi sekompleks pakaian pada saat dinasti Ming, karena banyak menyerap bentuk pakaian orang Manchu dan barat.Di awal abad ke-19, kegiatan berpergian meningkat karena banyaknya perusahaan kereta api beroperasi, orang mulai travelling dengan kereta dan kebutuhan untuk membawa barang bawaan pun meningkat. Laki-laki pada umumnya membawa barang bawaan dengan leather suitcase. Namun, kebutuhan untuk membawa barang bawaan bagi perempuan belum tercukupi. Purse dan pouch tidak lagi cukup untuk membawa barang-barang bawaan, maka lahirlah handbag. Handbag padamasa itu terbagi menjadi dua jenis, yaitu tanpa pegangan (handless) dan dengan pegangan. Model pertama yang pertama kali muncul umumnya adalah model tanpa pegangan. Seiring berjalannya waktu, dan kebutuhan akan barang bawaan semakin banyak, maka muncul model dengan pegangan. Setelah Perang Dunia I, kaum perempuan mulai semakin banyak yang berpergian, hal ini menyebabkan munculnya banyak variasi handbag. Pada umumnya tas pada zaman itu menggunakan teknik embroidery dengan warna benang yang berwarna-warni dan juga pilinan benang emas dan perak. Motif-motifnya menunjukan bentuk bunga, figur,dan hewan seperti burung, bebek, atau naga. 

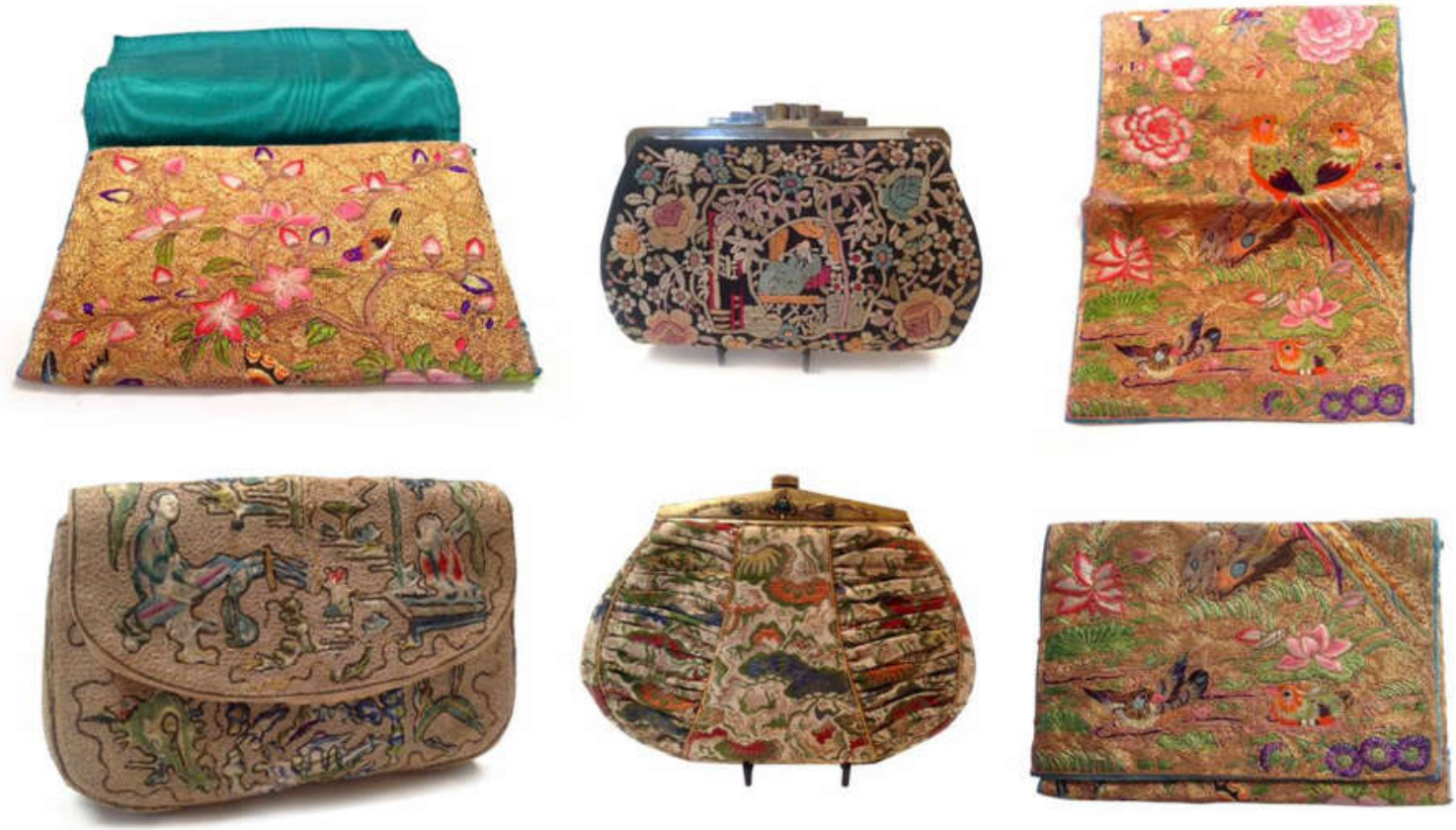

Gambar 6. Handbag Tanpa Pegangan

Sumber: www.thepursemuseum.com, 21-3-2013, 18.30
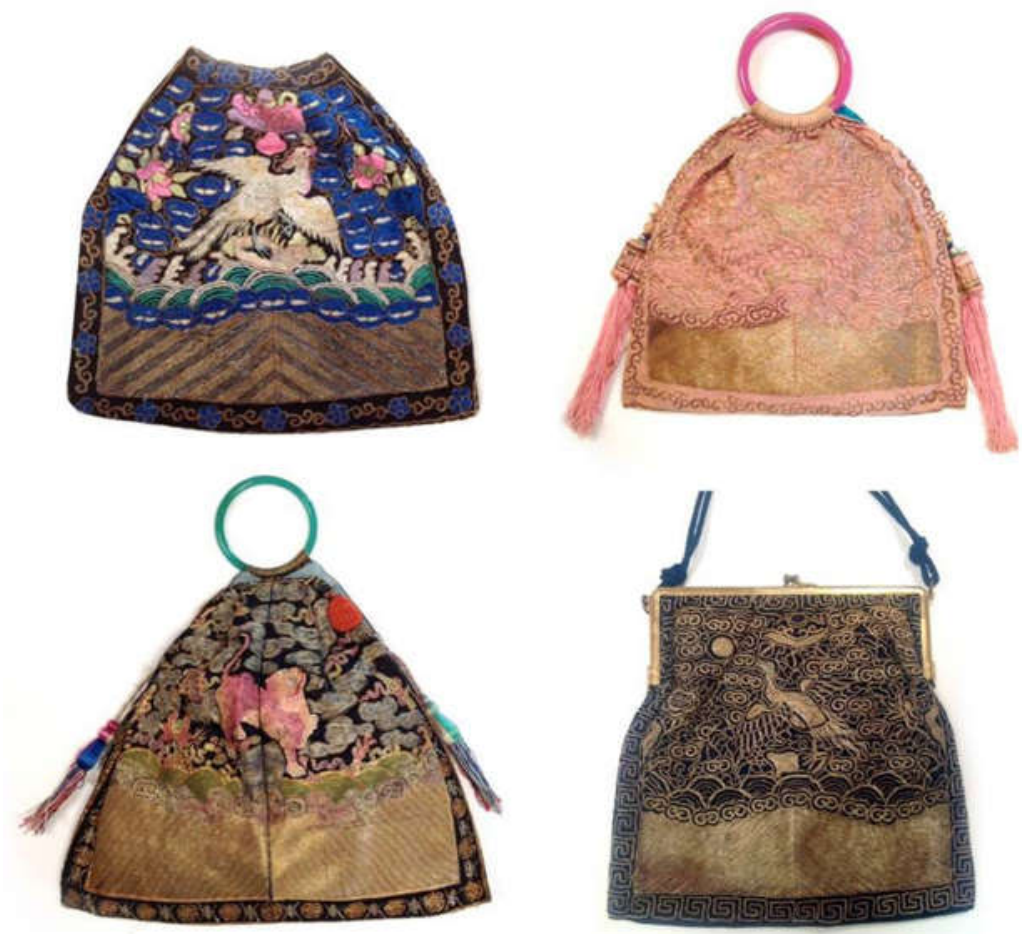

Gambar 7. Handbag Dengan Pegangan

Sumber: www.thepursemuseum.com, 21-3-2013, 18.30 
Perang Dunia II membawa pengaruh baru dalam dunia fashion. Sekitar tahun 1940an, setelah Perang Dunia II berakhir, dunia fashion kuat dipengaruhi oleh military look. Hal ini terlihat pada bentuk pakaian yang lebih sederhana dan mengikuti kontur tubuh, tidak menggunakan kain yang berlebihan seperti zaman yang terdahulu. Bentuk tas pun lebih mengikuti fungsi dari barang bawaan, dengan model yang lebih praktis dan sederhana, serta ukuran yang lebih besar. Runtuhnya dinasti Qing dan kemerdakaan RRC juga mengambil andil dalam peran masuknya pengaruh budaya barat bagi Cina, sehingga proses westernisasi dan modernisasi berlangsung dan mengakibatkan perubahan yang besar dalam dunia fashion di Cina.

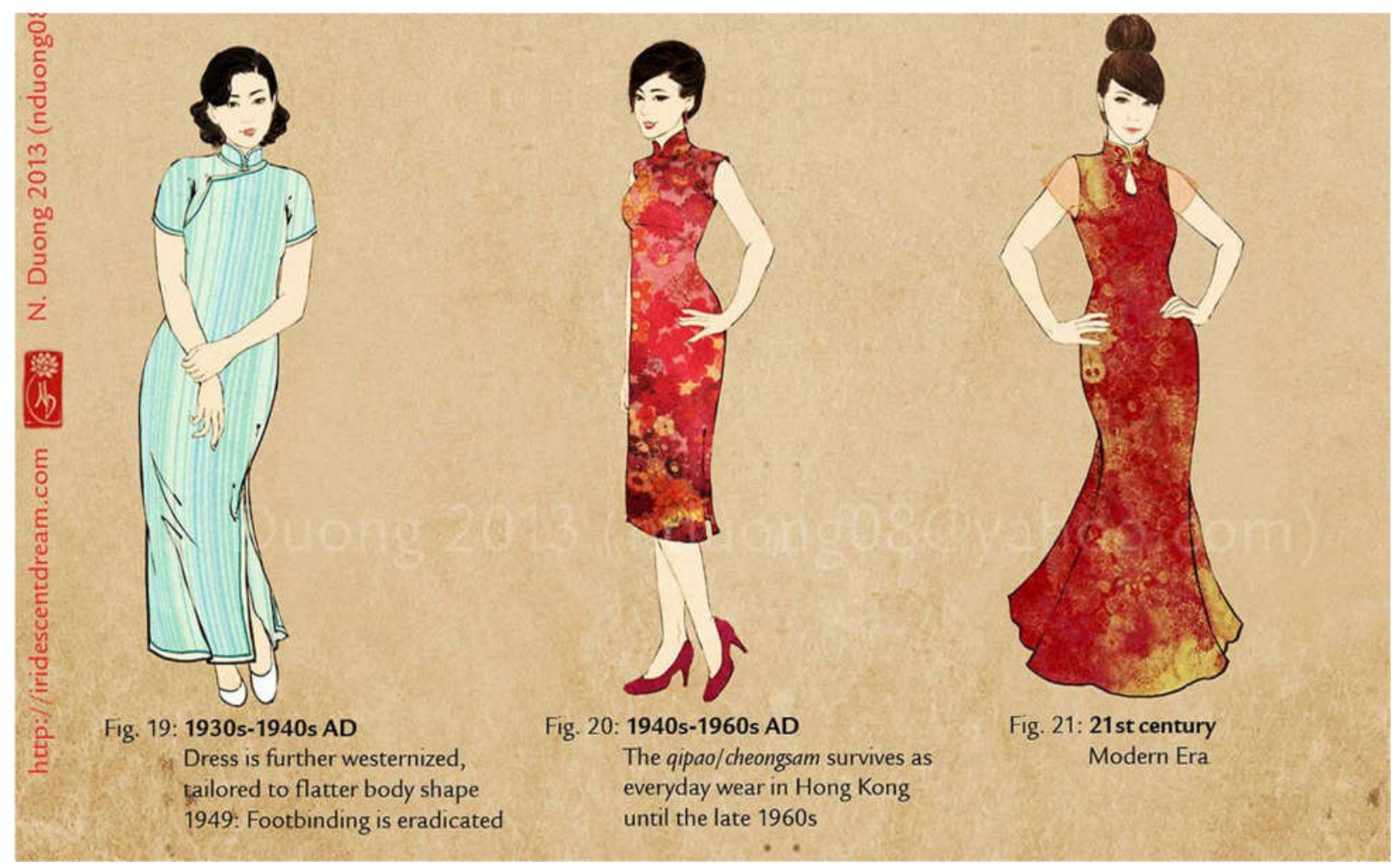

Gambar 8. Perkembangan Busana Cina setelah Kemerdekaan

Sumber:www.1860-1960.com, 16-3-2013, 15.30

Perkembangan pakaian setelah Perang Dunia II memberi pengaruh kepada bentuk tas. Bentuk shoulder bag muncul karena pengaruh dari bentuk tas militer dari Perang Dunia II, sehingga cara membawa tas pada zaman ini disandangkan di bahu. 

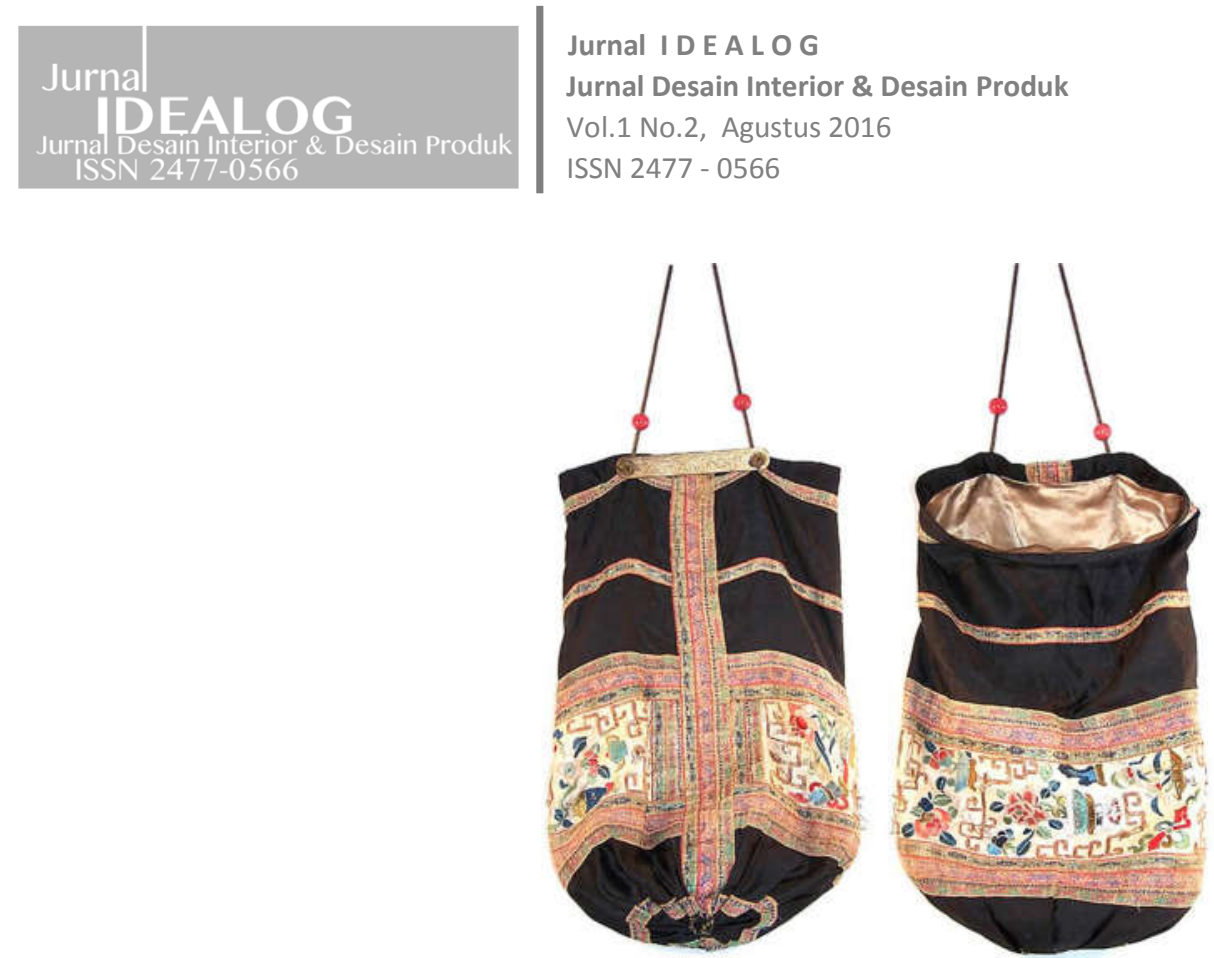

Gambar 9. Bentuk Tas Menjelang Abad ke-20

Sumber: www.1860-1960.com, 16-3-2013, 15.30

Memasuki abad ke-20 dan abad ke-21, unsur ornamental pada tas Cina sangat berkurang drastis, jarang ditemui teknik embroidery dan beadwork yang dulu menjadi fokus utama dalam perancangan tas. Modelnya mengikuti bentuk minimalis yang dipengaruhi budaya barat, dengan bentuk dasar persegi panjang.

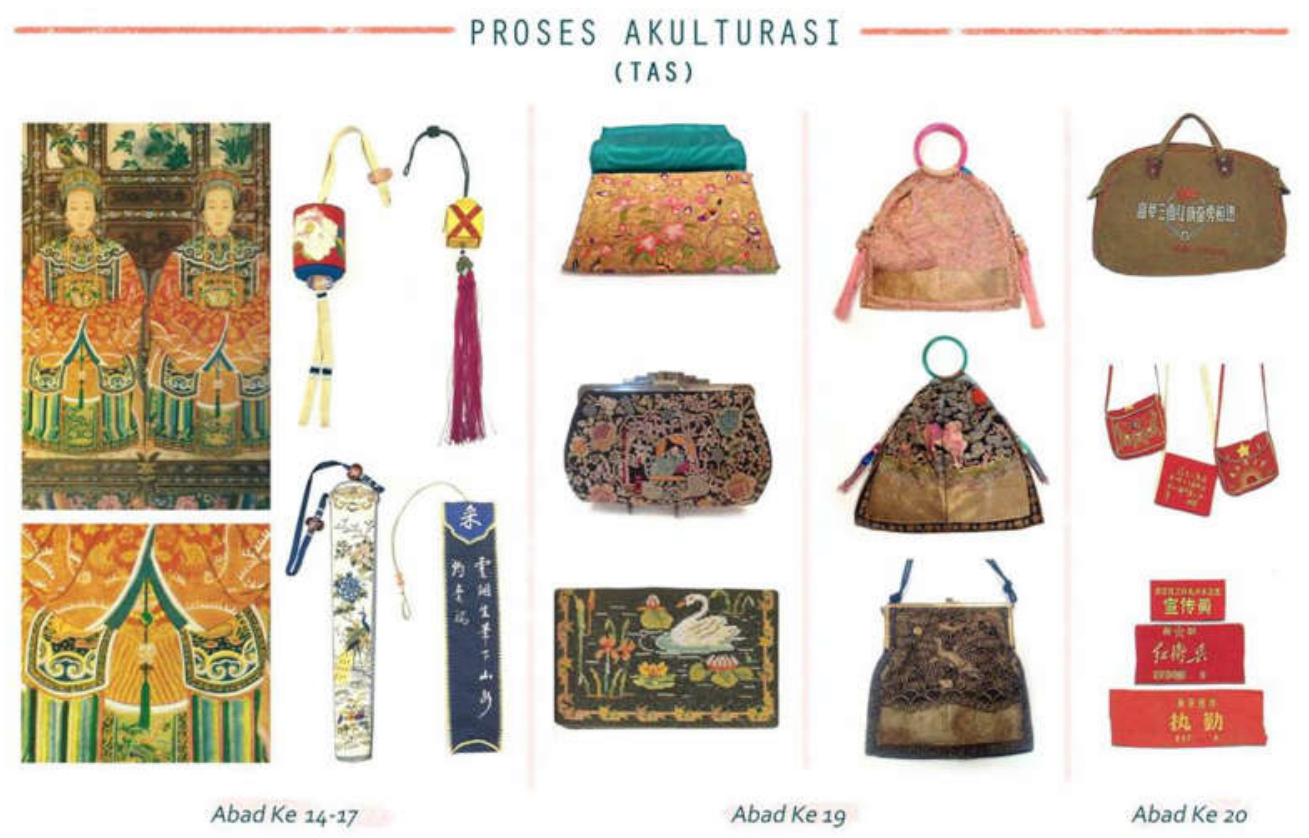

Gambar 10. Timeline Tas Cina

Sumber: Data Pribadi, 2013 


\subsection{Tas dalam Budaya Cina Peranakan}

Perkembangan tas pada budaya Cina peranakan yang berkembang di Nusantara erat kaitannya dengan perkembangan bentuk tas yang ada di Cina. Ketika awal kedatangan orang Cina di Nusantara sebelum masuknya Belanda dan negeri Barat lainnya, tas yang dipakai oleh kaum perempuan Cina adalah tas dengan model dan bentuk yang dipengaruhi oleh tas pada kebudayaan Cina. Warna yang mendominasi adalah merah dan emas, atau biru dengan emas, dengan bentuk ornamental Cina seperti burung phoenix, naga peony dan lain sebagainya.

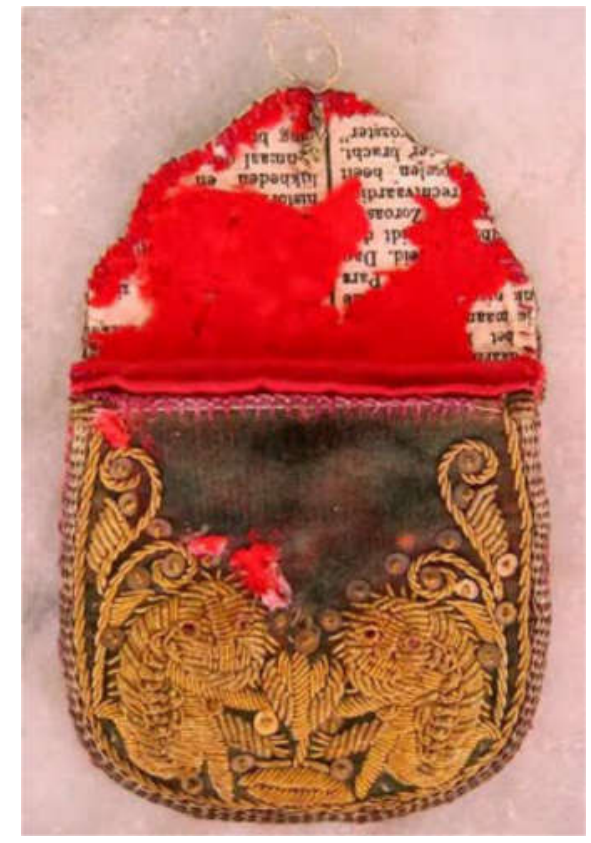

Gambar 11. Tas Cina Peranakan Abad ke-7

Sumber: Chinese Dress "From the Qing Dynasty to the Present", 2008

Sekitar awal abad ke-19, ketika orang Eropa mulai banyak di kawasan Nusantara, bentuk tas berkembang dari segi motif, dimana muncul motif-motif yang dipengaruhi oleh budaya Eropa. Contohnya adalah bunga peony digantikan oleh motif bunga mawar, atau bebek digantikan dengan swan. Namun, bentuk dari tas itu sendiri mengikuti bentuk tas yang sedang berkembang di negeri Cina, yaitu bentuk tas handless atau disebut juga clutch bag. Berbeda dengan negeri Cina dimana lebih sering dijumpai teknik embroidery atau jahitan dengan pilinan benang emas, kaum Cina peranakan menggunakan teknik beadwork, seperti teknik yang digunakan untuk membuat kasut manek. Jenis beads yang digunakan merupakan Rocaille beads, yang didatangkan oleh pedagang melalui hubungan perniagaan dari Eropa. Beads ini disebut oleh kaum Cina peranakan sendiri adalah manik potong. Manik dalam bahasa Melayu berarti beads atau mote, sedangkan potong mengartikan 'cut beads'. 

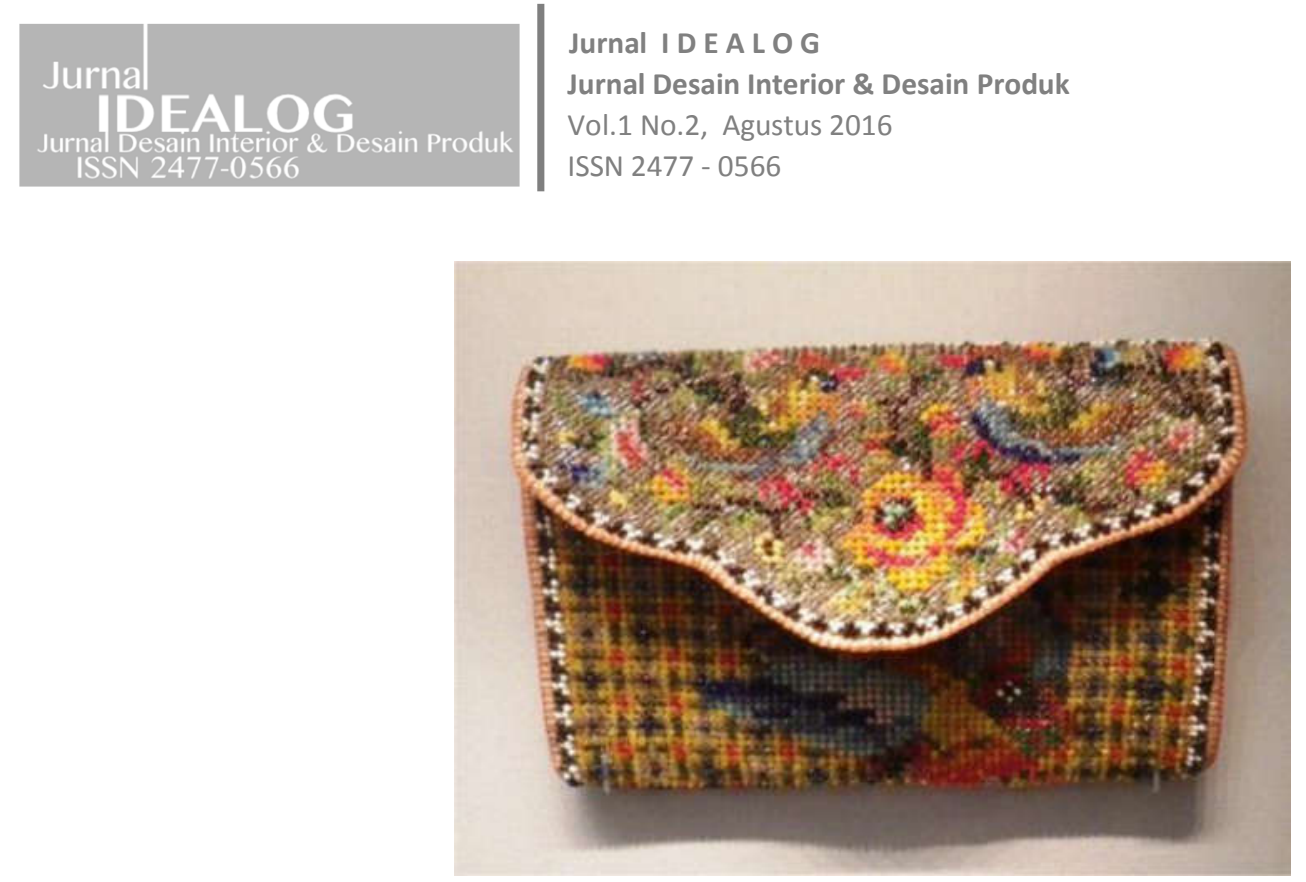

Gambar 11. Tas Cina Peranakan Abad ke-19 Sumber: www.jualsepedaonthelantik.blogspot.com

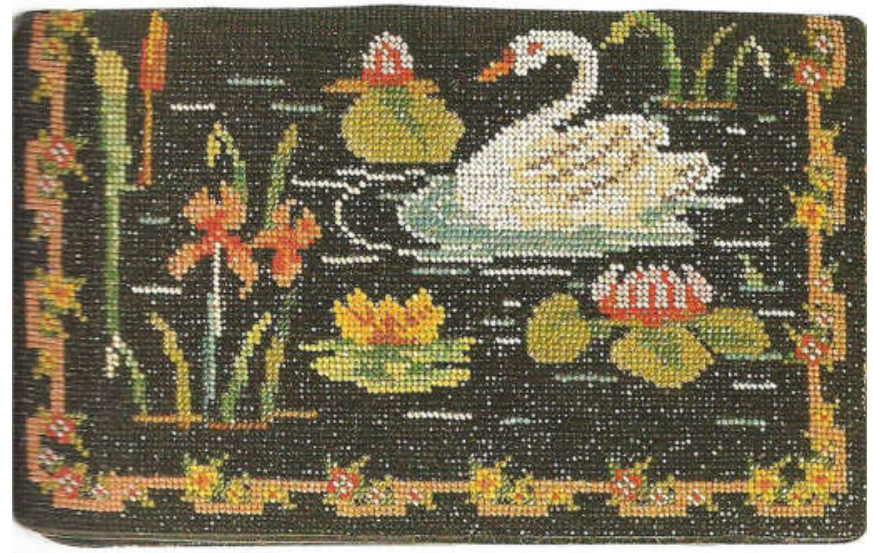

Gambar 12. Beadwork Pouch

Sumber: The Nyonya Kebaya, 2004

Beadwork merupakan suatu keterampilan yang kini hampir punah (Mahmood, 2004). Kehadiran Rocaille beads telah digantikan oleh beads plastik dengan ukuran yang besar-besar. Selain bentuk tas dengan teknik beadwork, ada pula tas dari bahan logam pada masa itu.

Jenis logam yang sering dijumpai pada kultur peranakan Tionghoa bervariasi mulai dari logam berharga seperti emas dan perak sampai timah dan kuningan. Juga perunggu, alpaca (perak nikel) atau pewter ('O9OUcampuran timah putih dan timah hitam) (Musa, Jonathan, dkk).

Emas umumnya digunakan sangat terbatas hanya pada perhiasan untuk kepentingan seremonial atau pesta. Itupun hanya golongan masyarakat kelas atas yang menggunakannya. Masyarakat biasa rata-rata menggunakan bahan perak dilapis emas atau emas sepuhan untuk pernakpernik perhiasan. 

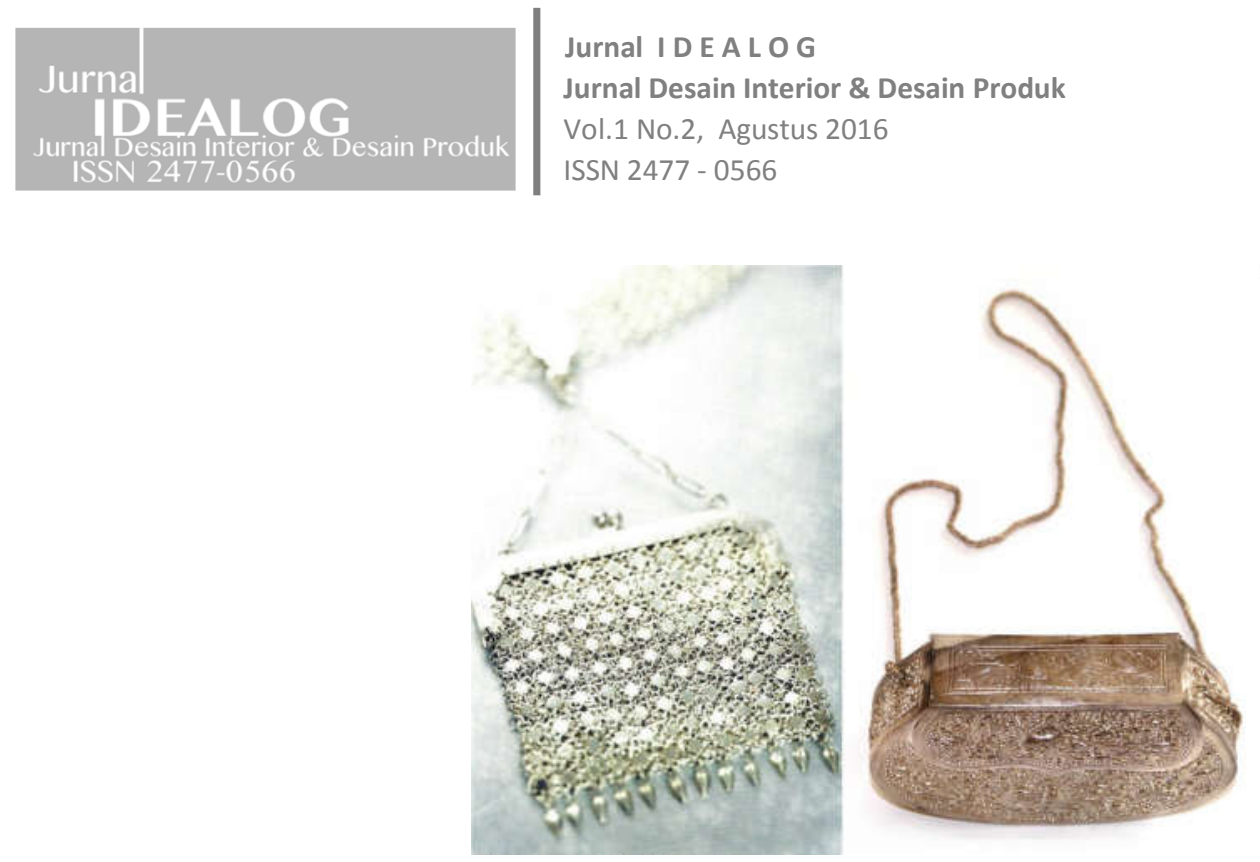

Gambar 13. Logam Pouch

Sumber: The Nyonya Kebaya, 2004

\section{Pembahasan}

Pembahasan dari hasil studi literatur yang dilakukan proses alkuturasi beserta faktor faktor yang mempengaruhinya.

$$
\text { PROSES AKULTURASI }
$$
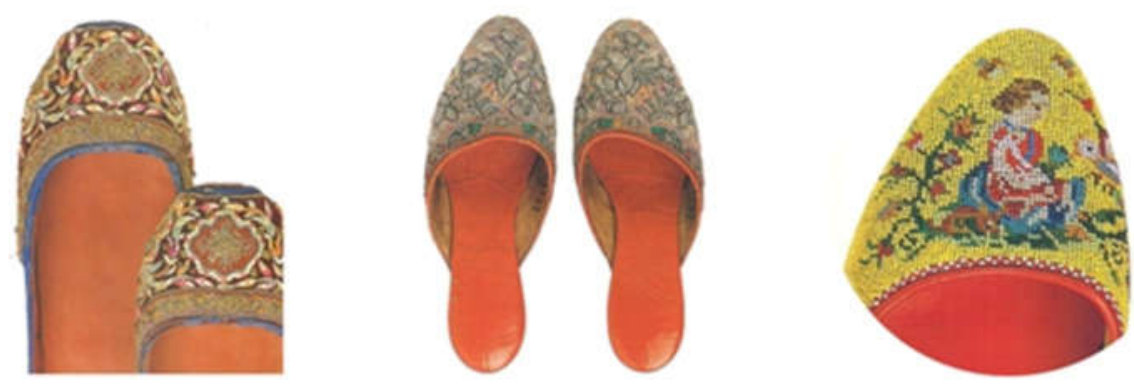

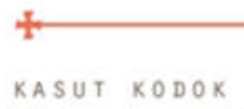

Bentuknya merupakan persilangan antaro slip-on-foe dan slipper. disebut juga dengan sebutan kasut tongkang (Chinese bumboat shoes).

$$
\begin{aligned}
& A B A D \\
& K E-5
\end{aligned}
$$

KASUT MANEK

\section{KASUT SERET}

Bentuknya menyerupai alas kaki yang biasa digunakan di kamar hotel. dengan unsur ornamental yang menggunakan feknik embroidery. 


\begin{tabular}{|c|c|c|}
\hline Produk Fesyen & Karakter Fisik & Asimilasi Budaya \\
\hline $\begin{array}{l}\text { Alas kaki } \\
\text { (kasut } \\
\text { manek) }\end{array}$ & \begin{tabular}{|ll} 
- & Bentuk U pada \\
& bagian depan kasut \\
& kodok (sebelum \\
& adanya kasut manek) \\
- & Teknik beadwork \\
- & Motif kisah atau cerita dan \\
& lingkungan \\
- & Material kulit sebagai \\
- & alas atau sol
\end{tabular} & $\begin{array}{ll}\text { - } & \text { Terinspirasi dari bentuk } \\
\text { bagian depan ballerina } \\
\text { shoes orang barat } \\
\text { - } \quad \text { Keterampilan yang wajib } \\
\text { dimiliki kaum nyonya } \\
\text { - } \quad \text { Terinspirasi dari } \\
\text { dongengdongeng } \\
\text { barat seperti LittleRed } \\
\text { Riding Hood atau Hansel } \\
\text { and Gretel } \\
\text { - } \quad \text { Material yang kuat (sering } \\
\text { - } \\
\text { digunakan sebagai material } \\
\text { - } \\
\text { suitcase dan coat orang } \\
\text { barat) }\end{array}$ \\
\hline
\end{tabular}

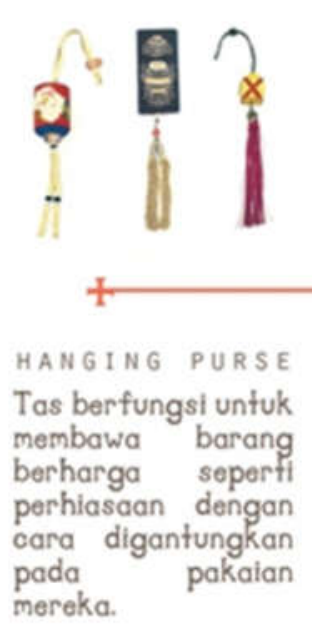

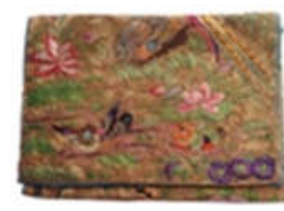

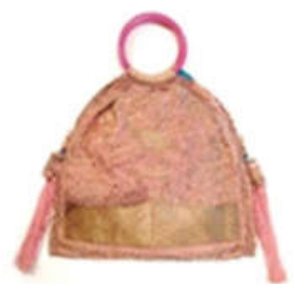

H A N D B A G

Tas yang muncul setelah PD I ketika orang semakin banyak berpergian. Benfuk tas ini tanpa pegangan dengan unsur ornamental dan teknik embroidery.

Pengembangan dari
benfuk clutch bag.
dengan berukuran
lebih besar dan
dengan pegangan
untuk memudahkan
karena beban
bawaan yang ber-
tambah.

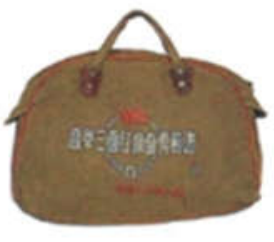

MODERN BAG

Setelah PD II. bentuk tas mengalami perubahan dipengaruhi cara tentara membawa barang bawaan yang sistematis. sehingga unsur ornamental bergeser ke fungsi. 


\begin{tabular}{|l|ll|l|}
\hline \multicolumn{2}{|c|}{ Produk Fesyen } & \multicolumn{1}{|c|}{ Karakter Fisik } & Asimilasi Budaya \\
\hline Tas & $\begin{array}{l}\text { Teknik beadwork } \\
\text { - }\end{array}$ & $-\begin{array}{l}\text { Kotif bunga mawar, } \\
\text { bunga daisy, dan swan } \\
\text { wajib } \\
\text { dimiliki kaum nyonya } \\
\text { Pengaruh motif }\end{array}$ \\
& & & $\begin{array}{l}\text { Pudaya barat } \\
\text { butang }\end{array}$ \\
\hline
\end{tabular}

\section{Kesimpulan}

Budaya cina peranakan adalah salah satu budaya Indonesia yang sangat menarik dan sangat kaya karena budaya Cina peranakan merupakan silang budaysa antara budaya Indonesia (mayoritas Jawa), budaya barat (mayoritas Belanda), dan budaya Cina. Faktor sejarah seperti masa pendudukan Belanda sangat mempengaruhi asimilasi artefak produk budaya seperti kasut manek bentuknya terinspirasi sepatu balet yang di kala itu sangat popular di Eropa dan teknik pembuatannya adalah teknik embroidery dan beadwork yang berasal dari Cina. Kedua teknik keterampilan yang wajib dimiliki wanita turunan Cina (Cina Peranakan).

\section{Referensi}

[1] Aspertina. "Budaya Cina Peranakan di Indonesia", Aspertina Online. Home page on-line. Available from http://aspertina.com/; Internet, accessed 12 April 2013.

[2] Davonar, Agnes. Kisah Tragis Oei Hui Lan, Putri Orang Terkaya di Indonesia., Jakarta: Intibook, 2009.

[3] Doellah, H. Santosa. Batik: Pengaruh Zaman dan Lingkungan. Surakarta: Batik.

[4] Danar Hadi, 2002 Lim Lin, Lee Loh. The Blue Mansion: The Story of Mandarin Splendour Reborn. Michigan: L'Plan, 2002.

[5] Garrett, Valery. From the Qing Dynasty to the Present. Turtle Publishing, 2007.

[6] Groeneveldt, W.P. Nusantara dalam Catatan Tionghoa. Jakarta: Komunitas Bambu. 2009.

[7] Jiamian, Zou. Traditional Chinese Patterns and Colours. Singapore: Page One, 2010

[8] Kwa, David. Peranakan Tionghoa Indonesia, Sebuah Perjulanan Budaya, Jakarta: Intisari, 2009.

[9] Mahmood, Datin Seri Endon. The Nyonya Kebaya. Singapore: Periplus. 2002. 


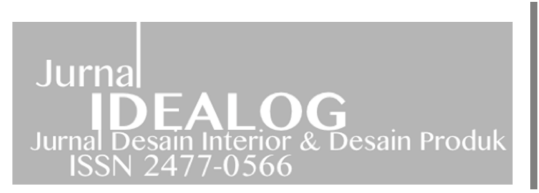

[10] Nyonya Peranakan. "Asimilasi Budaya Kaum Nyonya”, Nyonya Peranakan Online. Home page on-line. Available from http://www.nyonyaperanakan.com/; Internet, accessed 4 April 2013.

[11] Peranakan Museum. "Budaya Cina Peranakan", Peranakan Museum Online.

[12] Sunaryo, Aryo, Ornamen Nusantara, Dahara Prize, Jakarta, 2010 Square, Vicki. Folk Bags: 30 Knitting Patterns and Tales from Around the World. LLC: Interweave, 2003.Phoenix and Peony. "Arti Simbol Cina", Phoenix and Peony Online. Home page on-line. Availabl e from http://www.pheonixandpeony.com/; Internet, accessed 1 Juni 2013.

[13] Tassen Museum. "History of Bag", Tassen Museum Online. Home page on-line.. Available from http://www.tassenmuseum.nl/en/education; Internet, accessed 2 Juni 2013.

[14] Wacik, Triesna Jero. Adikarya Sulam Indonesia. Yayasan Sulam Indonesia: Jakarta 2012.

[15] Williams, C.A.S. Chinese Symbolism and Art Motifs. Singapura: Tuttle Publishing, 2006 